\title{
Rabasa Gamboa, Emilio, Las reformas constitu- cionales en materia político-electoral, Programa de las Naciones Unidas para el Desarrollo-UNAM, Instituto de Investigaciones Jurídicas, 2012, 94 pp. [Prólogo de Jorge Alcocer]
}

Emilio Rabasa Gamboa nos entrega una obra en la que de manera didáctica revisa de forma cronológica, ordenada y sistemática la trayectoria del cambio constitucional en materia electoral. Se trata de un texto en el que la revisión comprende desde la reforma de principios de la década de los años cincuenta del siglo pasado, hasta la más reciente de 2007, la cual introduce un novedoso y avanzado modelo de comunicación política. El doctor Rabasa nos conduce paso a paso por la historia, siempre en movimiento, del sistema electoral mexicano.

Edición bilingüe español-inglés, destaca la obra que el activismo reformista-constitucional es un signo inequívoco de la dinámica que ha tenido el sistema político mexicano a partir de la segunda mitad del siglo XX. La historia de estas reformas es de hecho la historia de la evolución de un sistema altamente centralizado y autoritario a uno descentralizado y democrático. En esta transformación el acento está puesto sobre todo en el papel relevante de los partidos políticos, pero no menos importantes han sido los órganos electorales y el sistema de jurisdicción electoral.

Bajo la óptica del autor, el conjunto de las reformas político-electorales puede dividirse en dos etapas: la primera abarca desde 1953 hasta 1977, son reformas aisladas del sistema electoral que abordan aspectos parciales, de manera particular el ensanchamiento de la base 
electoral referida a los derechos políticos activos y pasivos. La segunda etapa que inicia a partir de la reforma de 1977 se caracteriza por modificaciones más extensas que afectan al sistema electoral en su conjunto.

Según se aprecia en el texto, las reformas electorales parciales fueron cuatro: la de 1953 a los artículos 34 y 115 constitucionales, que otorgó a las mujeres el derecho activo de votar y el pasivo de ser electas para cualquier cargo de elección popular. Quedaba así asegurada la extensión del voto a la mujer al enlazarse los artículos 34 y 35 constitucionales. La reforma de 1963 al artículo 54 constitucional que introduce el sistema de diputados de partido. Previo a esa modificación era casi imposible el acceso a la Cámara de Diputados de diversos partidos políticos o corrientes de opinión distintos del partido oficial. Este sistema de diputados de partido fue el antecedente del sistema mixto de mayoría y representación proporcional que se introdujo con la reforma de 1977. En 1969 se reforma el artículo 34 constitucional, fracción I, que otorga la prerrogativa de votar a los jóvenes de dieciocho años, pero no el derecho pasivo de ser votado. Con la reforma de 1972 se reduce la edad para ser electo diputado de veinticinco a veintiún años cumplidos y para ser electo senador, de treinta y cinco a treinta años cumplidos. Esta reforma también se extendió al sistema de diputados de partido, reduciendo el porcentaje requerido para acreditarlos de $2.5 \%$ a $1.5 \%$, se aumentó el tope máximo de diputados que un partido podía acreditar por este sistema, de veinte a veinticinco.

Mediante estas cuatro reformas el sistema electoral mexicano amplió los derechos políticos activos y pasivos. Hacia 1976 México tenía un sistema electoral más amplio, pero no por ello más justo, imparcial, equitativo y, sobre todo, más competitivo. Como lo refiere el autor, las siguientes reformas estarían encaminadas a lograr estos valores indiscutibles en un sistema democrático electoral moderno.

Común denominador de las reformas integrales a partir de 1977, su amplitud y profundidad abarcaron al sistema electoral en su conjunto y aspectos medulares como el subsistema de partidos políticos y sus prerrogativas, el subsistema de órganos electorales, el procedimiento electoral, el sistema de elección de diputados y senadores al Congreso de la Unión, y el subsistema contencioso electoral. Sin abandonar la orientación didáctica, Emilio Rabasa expone con pulcritud y acierto las siete reformas político-electorales integrales. 
Reforma de importancia sustantiva para la evolución del sistema político mexicano, al dar un gran paso en su liberalización, las modificaciones de 1977 logran la inserción de los partidos políticos al texto constitucional, y establecen el sistema mixto de mayoría relativa y representación proporcional. Fue hasta la reforma de 1963 cuando se incluyó en el texto constitucional a los partidos políticos, pero sólo con relación al sistema de diputados de partido. En la reforma de 1977 al artículo 41 constitucional, se insertó de plano a los partidos políticos como entidades de interés público. El significado de esta reforma fue reconocer la importancia que tienen los partidos políticos para configurar la representación nacional.

Otro aspecto toral de la reforma fue el desarrollo del sistema de mayoría relativa y representación proporcional para la integración de la Cámara de Diputados. El sistema implantado consistió en elegir a 300 diputados según el principio de votación mayoritaria relativa y hasta 100 diputados electos conforme el principio de representación proporcional. Las reglas para tener acceso al sistema de representación proporcional quedaron establecidas en el artículo 54 constitucional. En los términos como quedó planteada la reforma, el entonces partido mayoritario no podía acceder a la representación proporcional. La oposición tendría aseguradas 100 curules de representación proporcional, aumentando su anterior presencia de 25 diputados de partido.

Sin mayor efecto en la práctica, la reforma de 1977 establece en el artículo 73 constitucional, fracción VI, el referéndum y la iniciativa popular; figuras democráticas revaloradas años más tarde. Sin trastocar el procedimiento de calificación de las elecciones, prevaleció el sistema de autocalificación de cada Cámara. En materia de jurisdiccional electoral esta reforma involucró a la Suprema Corte de Justicia de la Nación en dos sentidos; mediante el recurso de reclamación podrían impugnarse las resoluciones del Colegio Electoral de la Cámara de Diputados, sin embargo, la resolución sólo tendría efectos declarativos; por otra parte, se facultó a la Suprema Corte para practicar de oficio la averiguación de algún hecho o hechos que constituyan violación del voto público.

Conservando los avances de la reforma anterior, en cierto sentido, los principales méritos de la reforma de 1986 se localizan en la materia jurisdiccional y el inicio de la democratización del Distrito Federal. No obstante, como lo indica el autor, sus logros no pudieron sobreponerse a las faltas, en el tema de la organización electoral la reforma 
conlleva una regresión. En el último párrafo del artículo 60 se estableció la rectoría del gobierno federal en todo el proceso electoral.

Durante el sexenio de 1988 a 1994 se llevaron a cabo tres reformas electorales. Fueron una serie de reformas de tonos claroscuros; por un lado, se mantuvo la integración inequitativa que contribuyó a la parcialidad de los órganos electorales, hasta que en 1994 se decidió la ciudadanización del Instituto Federal Electoral. Por otro, se abrió el Senado a cierto grado de pluralidad mediante la figura del senador de primera minoría. En este grupo de reformas se canceló la cláusula de gobernabilidad pero se mantuvo la sobrerrepresentación en la Cámara de Diputados. La reforma de 1994 resultó la más significativa de las tres, al avanzar en el principio de imparcialidad de la organización electoral a través de la figura del consejero ciudadano.

Recuperando el orden cronológico, la reforma de 1990 reestructuró todo el aparato electoral. La competencia para organizar elecciones se cambia de la exclusividad del gobierno federal a la corresponsabilidad con los partidos políticos y ciudadanos. Al decidir la integración de un organismo público denominado Instituto Federal Electoral (IFE), la reforma estableció que las elecciones se regirán por cinco principios: certeza, legalidad, imparcialidad, objetividad y profesionalismo. A pesar de lo anterior, el organismo electoral careció de un auténtico sello ciudadano. La reforma de 1990 buscó combinar el principio de gobernabilidad en la Asamblea del Distrito Federal con una distribución de curules acorde al porcentaje de la votación obtenida y el número de constancias de mayoría. En el terreno de lo contencioso electoral se amplían los medios de impugnación y se decide la desconcentración del Tribunal Electoral.

Por primera vez en la historia de la Cámara de Senadores, la reforma de 1993 determina su integración por cuatro miembros representantes de cada estado y el Distrito Federal; tres serían por el principio de mayoría relativa y uno asignado a la primera minoría. Esta reforma suprime el procedimiento de autocalificación de diputados y senadores por los colegios electorales respectivos y en su lugar se establece un sistema de heterocalificación electoral mixto, a cargo de un órgano autónomo electoral y del Tribunal Electoral. Además de suprimir la cláusula de gobernabilidad, poniendo fin a la etapa de las reformas constitucionales monopartidistas, se reestructura y recompone la competencia del Tribunal Federal Electoral como órgano autónomo y máxima autoridad jurisdiccional en la materia. 
Más significativa que las dos reformas anteriores, la de 1994 modificó el principio organizativo electoral. El desplazamiento de la organización electoral hacia el IFE fue de la mayor significación política, ya que marcó el inicio del proceso de desprendimiento y autonomía de los órganos electorales respecto del gobierno federal. El órgano superior de dirección del IFE se integraría ahora por la nueva figura del "consejero ciudadano", que no sólo sustituyó al consejero magistrado sino que adquirió el control mayoritario del máximo órgano electoral. Debido al peso mayoritario de los consejeros ciudadanos se "ciudadanizó" el sistema electoral al decrecer el peso específico del gobierno federal y el de los mismos partidos políticos.

Señalada en su tiempo como la reforma electoral definitiva, uno de los grandes aciertos de la reforma constitucional electoral de 1996 fue haber logrado el consenso de los cuatro partidos políticos: PAN, PRI, PRD y PT. Cabe destacar que los avances alcanzados con esta reforma no se limitan al ámbito federal, su federalización impacta en diferentes incisos a las elecciones locales con la modificación al artículo 116 constitucional, fracción IV.

Conservando la autoridad de la función electoral en el IFE, el cambio fundamental de la reforma de 1996 consistió en haber sacado la participación del Poder Ejecutivo, el Consejo General del instituto se integra por un consejero presidente y ocho consejeros generales, únicos miembros con derecho a voz y voto. Mediante el control ciudadano, la nula representación del Ejecutivo federal, mínima del Congreso y representación partidista sin voto, se consigue una autonomía más auténtica del órgano electoral.

Relativa a las nuevas reglas de equidad en la competencia electoral, la reforma abundó en el nivel constitucional modificando las reglas del financiamiento a los partidos. Mediante dos principios se determinó la preferencia del financiamiento público sobre el privado y el destino de los recursos para el sostenimiento de actividades ordinarias permanentes y de aquellas tendentes a la obtención del voto. De forma colateral, en el Código Federal de Instituciones y Procedimientos Electorales (Cofipe) se establecieron los límites de gastos de campaña.

Dirigidas al pluralismo político, las modificaciones constitucionales que introduce la reforma fueron las siguientes: disminuye de 315 a 300 el número máximo de diputados que pudiera tener un solo partido; introduce un nuevo principio de equidad distributiva de las curules, el porcentaje total de escaños se vincularía al porcentaje de la 
votación nacional emitida, de tal suerte que ningún partido político pudiera obtener más diputados que el reportado por su votación más un $8 \%$; abunda también en la pluralidad del senado al someter la distribución de 32 senadores al principio de representación proporcional, en adición a los 32 que se repartirían a la primera minoría y los 68 de mayoría relativa.

Fiel al sentido didáctico de la obra, Emilio Rabasa expone que uno de los elementos trascendentales de la reforma constitucional de 1996 fue la modificación al artículo 122, sobre todo en la parte conducente a la elección del jefe de gobierno del Distrito Federal, quien será electo mediante votación universal, libre, directa y secreta. La reforma incluye la precisión del sistema de competencias concurrentes entre los poderes de la unión y las autoridades locales, así como la conversión de la Asamblea de Representantes en Asamblea Legislativa.

En materia de jurisdicción electoral las innovaciones de la presente reforma versan sobre la constitucionalidad de las leyes electorales y la ubicación del Tribunal Electoral como parte del Poder Judicial. Haciendo extensivas las acciones de inconstitucionalidad a los partidos políticos nacionales contra leyes federales o locales y aquellos con registro estatal contra leyes locales, se reafirma la competencia exclusiva de la Suprema Corte de Justicia. Desde 1996 corresponde al Tribunal Electoral del Poder Judicial de la Federación realizar el cómputo de la elección presidencial, formular la declaración de validez de la elección y la constancia de mayoría para el presidente electo. A partir de entonces esta alta responsabilidad queda ahora en manos de siete magistrados.

Con suficiente mérito destaca el autor que la reforma constitucional de 2007 es la primera que no obedece a una iniciativa del titular del Ejecutivo Federal, sino de los propios legisladores de los diferentes partidos políticos. A diferencia de las anteriores que siempre introdujeron un cambio o innovación en las estructuras electorales o el sistema de representación nacional, ésta se dirigió a realizar una serie de ajustes en materia de acceso a medios y financiamiento de campañas electorales.

Manteniendo el principio de que los recursos públicos deben prevalecer sobre los privados, se profundiza en el criterio de distribución de los recursos entre los partidos políticos, con esta reforma se fija un techo presupuestal para este gasto al determinar que el financiamiento para actividades ordinarias de los partidos, resulta de multiplicar 
el número total de ciudadanos inscritos en el padrón electoral por el $65 \%$ del salario mínimo vigente para el Distrito Federal. Se trata de un mecanismo de control del gasto en estas actividades que busca abaratar una democracia excesivamente cara.

En lo que se refiere a actividades para la obtención del voto, los recursos se reducen al 50\% de los destinados a las actividades ordinarias, tratándose de la elección presidencial, si es elección intermedia de diputados federales se asignará un 30\% de los recursos descritos. Más allá de las actividades mencionadas, la reforma fija un monto no superior al $10 \%$ de lo erogado en la elección interna anterior para los gastos de selección de candidatos de los partidos políticos. Tema sobresaliente, se consignó el principio del retorno a la Federación de los bienes de los partidos que hubieren perdido su registro. Previo a la reforma todos estos bienes quedaban en propiedad privada de los dirigentes del partido. Gran parte de la reforma está orientada de manera clara al ahorro de los gastos destinados a las diversas actividades de los partidos políticos.

Como lo destaca Emilio Rabasa, esta reforma modifica por completo el uso permanente de los medios de comunicación social por parte de los partidos políticos. Se introduce el principio general de que ahora es el IFE la autoridad única para administrar el tiempo del Estado en radio y televisión. Ni los partidos por sí mismos o por terceras personas podrán adquirir tiempos, en cualquier modalidad, de radio o televisión. Quedan prohibidas incluso las transmisiones de estos mensajes contratados en el extranjero. Lo anterior no significa que el IFE goza de total discrecionalidad en la administración de los tiempos referidos, pues de acuerdo con la normativa aplicable la distribución de esta prerrogativa se hará conforme a las reglas previstas.

Incorporando una disminución de tiempos de campañas y precampañas, la regulación constitucional comprende la prohibición de propaganda denigrante de las instituciones o los propios partidos y calumniosa de las personas. De igual manera se prohíbe a los tres niveles de gobierno realizar propaganda de los programas gubernamentales durante las campañas electorales, con excepción de las relativas a la educación, salud o para la protección civil en caso de emergencia.

Mediante un repaso ágil y preciso de otros tópicos de la reforma constitucional de 2007, el autor expone lo relativo a la fiscalización de los recursos del IFE y de las finanzas de los partidos, destaca la creación de dos órganos fiscalizadores distintos, una Contraloría General 
para el primer caso y un órgano técnico-fiscalizador para el segundo. Abordando los cambios referidos a la duración en el cargo y la designación escalonada de los miembros del Consejo General del IFE, Rabasa pone énfasis en las nuevas atribuciones del Tribunal Electoral del Poder Judicial de la Federación. La reforma fortaleció el carácter constitucional de este órgano asignándole nuevas atribuciones: las salas del Tribunal pueden resolver ahora la no aplicación de una ley electoral contraria a la Constitución, sin perjuicio de lo dispuesto por el artículo 105 constitucional. Sobresale la facultad de atracción de la Sala Superior y, por primera vez, se reconoce en forma expresa la jurisdicción del Tribunal para atender denuncias de violaciones de derechos políticos ciudadanos por parte de los partidos políticos.

Concluye la obra con un capítulo dedicado a las conclusiones. Congruente con la calidad del texto, Emilio Rabasa expresa que un somero análisis retrospectivo nos revela, por lo menos, cinco procesos o tendencias que apuntan hacia la democratización del sistema político: 1) la imparcialidad de los órganos electorales a través de su ciudadanización; 2) la pluralidad política en ambas Cámaras del Congreso de la Unión y en las legislaturas estatales; 3 ) la equidad en la competencia electoral; 4) la elección popular directa del gobierno capitalino, y 5) un sistema autónomo y confiable de justicia electoral. Por encima de la relevancia cuantitativa las reformas tienen un significado cualitativo.

Libro de lectura obligada para quienes desean conocer la historia de las reformas constitucionales en materia electoral, la gran virtud de la obra es brindar al lector un repaso ágil del activismo reformista como signo inequívoco de la dinámica que ha tenido el sistema político mexicano a partir de la segunda mitad del siglo XX. Emilio Rabasa ofrece una herramienta de enorme valor para comprender el devenir democrático de nuestra nación. Como lo indica en la parte final del texto, las reformas constitucionales en materia política no se han agotado. Incluso se ha ido conformando una nueva agenda legislativa, a la que seguro se sumarán las nuevas inquietudes derivadas de la elección presidencial de 2012.

\section{Saúl Mandujano Rubio}

Profesor en la Facultad de Estudios Profesionales Acatlán de la UNAM 